\title{
Modelagem e simulação de instrumentos musicais utilizando filtros digitais
}

\author{
Gustavo de Melo Valeira e Marcio Eisencraft
}

\begin{abstract}
Resumo-Este trabalho de iniciação científica apresenta os resultados da simulação por meio de filtro digitais de um instrumento musical de corda. A resposta em freqüência do filtro é modelada a partir da Transformada de Fourier da resposta ao impulso do instrumento obtida batendo-se em uma das cordas. A comparação entre as saídas do filtro e do corpo do instrumento indica que este pode ser efetivamente modelado por filtros digitais.
\end{abstract}

Palavras-chave-Processamento de sinais musicais, modelagem de instrumentos musicais, filtros digitais.

Abstract-This short paper presents results of the simulation by digital filters of a musical string instrument. The frequency response of the filter is modeled using the Fourier Transform of the instrument's impulse response obtained beating in one of the strings. The comparison between filter and real instrument body outputs indicates that it can be effectively modeled by digital filters.

Keywords-Musical signal processing, musical instruments modeling, digital filters.

\section{INTRODUÇÃO}

A modelagem de instrumentos musicais utilizando filtros digitais tem gerado muitos artigos interessantes [1-3]. O objetivo deste trabalho é modelar digitalmente um baixo, criando uma entrada e um filtro que juntos gerem um sinal semelhante ao produzido pela corda $\mathrm{Si}$ deste instrumento. Os filtros digitais seletivos em frequiência têm a mesma função que o corpo do baixo ao receber um som: deixar passar determinadas faixas de freqüência e remover outras [4].

Sintetizadores simulam vários instrumentos musicais, como baixo, guitarra e violão. Para isso, usam filtros que criam uma determinada nota dependendo do instrumento selecionado pelo usuário [5]. Notas são os sons produzidos por instrumentos musicais e recebem nomes de acordo com sua freqüência fundamental. As sete notas principais são: Dó, Ré, Mi, Fá, Sol, Lá e $\mathrm{Si}$.

O uso de filtros digitais para a síntese de notas musicais tem uma série de vantagens práticas. Entre elas, destaca-se a facilidade em se mudar as características naturais de um instrumento, permitindo assim maiores variações do som gerado [5]. Além disso, podem-se simular diversos instrumentos musicais usando o mesmo equipamento, bastando para isso ajustar os coeficientes dos filtros para cada caso.

Na Seção II é examinada a obtenção da resposta em frequiência do instrumento em questão, o baixo. Na Seção III é discutido o projeto do filtro que simula o corpo do instrumento. $\mathrm{Na}$ Seção IV são descritas simulações que permitem comparar o

Gustavo de Melo Valeira e Marcio Eisencraft, Escola de Engenharia, Universidade Presbiteriana Mackenzie, São Paulo, Brasil, E-mails: gusval@mackenzie.br, marcioft@mackenzie.br. desempenho do filtro frente ao instrumento musical. Por fim, na Seção V, são traçadas conclusões acerca dos resultados deste trabalho.

\section{RESPOSTA EM FREQÜÊNCIA DO INSTRUMENTO}

Uma estimativa da resposta impulsiva do corpo do baixo ao se acionar a corda $\mathrm{Si}$ foi obtida batendo-se rapidamente na corda Si de um baixo Washburn ${ }^{\circledR}$ XB-125, de forma a simular um impulso. Para capturar este som foi usado um amplificador WarmMusic $^{\circledR} 108 \mathrm{rb}$ e um microfone SoundMax ${ }^{\circledR}$ Superbeam ${ }^{\circledR}$ ligado a entrada de microfone de uma placa de som Realtek ${ }^{\circledR}$ AC'97 com frequiência de amostragem de $44.1 \mathrm{kHz}$. O sinal normalizado obtido, $h_{s i}(t)$, é mostrado na Figura 1 .

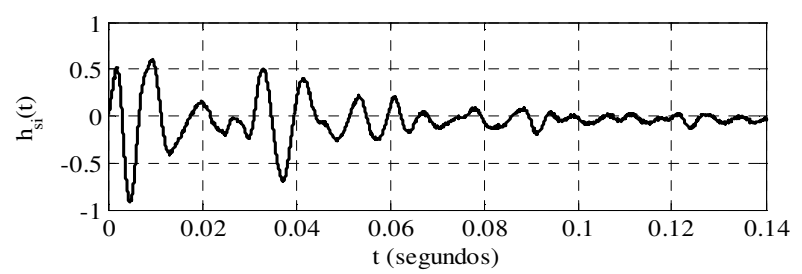

Fig. 1. Resposta ao impulso da corda Si do baixo.

Com a resposta impulsiva $h_{s i}(t)$ é possível obter a resposta em freqüência deste sistema, para que posteriormente projetese um filtro digital que corresponda de forma satisfatória a essa resposta. Para isso foi usada a Transformada Rápida de Fourier [4] e obteve-se a resposta em frequiência $H_{s i}(f)$, cujo módulo é mostrado na Figura 2.

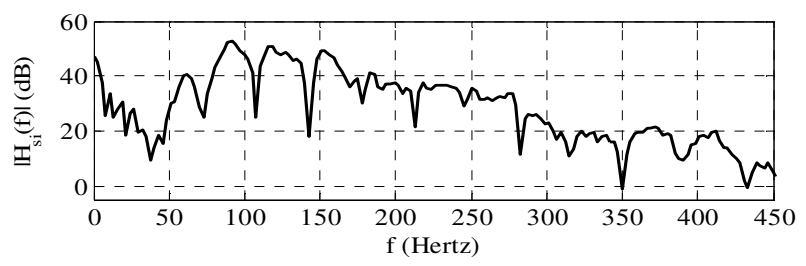

Fig. 2. Módulo da resposta em frequiência da corda Si.

\section{PROJETO DO FILTRO}

O espectro em frequiência da Figura 2 é usado como base para projetar um filtro digital correspondente ao corpo do baixo ao ser acionada a corda Si. Foram usados filtros de $2^{\mathrm{a}}$ ordem em cascata para simular o corpo do instrumento, como feito em [5].

Pela Figura 2 verifica-se que este espectro possui muitos vales anti-ressonantes e picos ressonantes. Dessa forma, é neces- 
sário projetar um filtro que selecione as faixas de freqüência mais relevantes das notas que a corda Si produz. Foram usados sete filtros em cascata usando o método de projeto descrito em [5], em que foi modelado um violão.

O módulo da resposta em frequiência $H_{F s i}(f)$ do filtro projetado é mostrado na Figura 3. Esta resposta é semelhante à da Figura 2 nas faixas de freqüência mais relevantes, ou seja, que contribuem mais para a resposta acústica do instrumento.

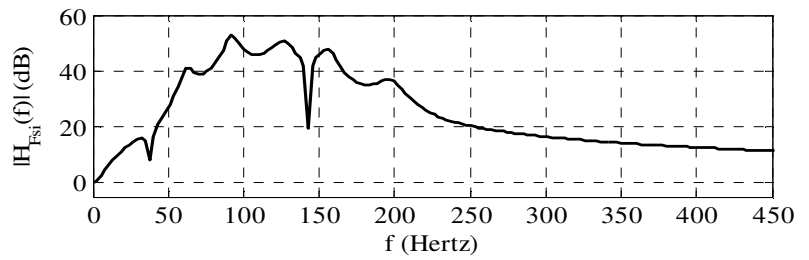

Fig. 3. Espectro em freqüência do filtro projetado.

\section{SimULAÇÕES}

Como o corpo do baixo está sendo modelado pelo filtro, espera-se que com uma entrada adequada, a saída do filtro seja um sinal semelhante ao som original do baixo.

A corda ao ser tocada produz uma frequiência fundamental e outras harmônicas, que são freqüências múltiplas da fundamental. A excitação gerada pela vibração da corda no corpo do instrumento é simulada aqui por um sinal dente de serra com freqüência igual à fundamental da nota. A amplitude da $n$-ésima harmônica no espectro deste sinal é proporcional a $1 / n$ [4]. O sinal dente de serra foi escolhido porque mostrou ser uma boa solução experimentalmente.

O resultado da filtragem $y_{\text {Filtro }}(t)$ de um dente de serra de $30.87 \mathrm{~Hz}$, que é a frequiência fundamental da nota Si mais grave do baixo, é apresentado na Figura 4(b). Na Figura 4(a) é mostrada a forma temporal do sinal $y_{s i}(t)$ relativo à nota $\mathrm{Si}$ produzida pelo baixo.

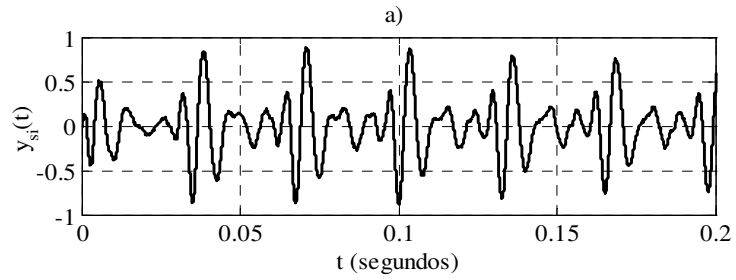

b)

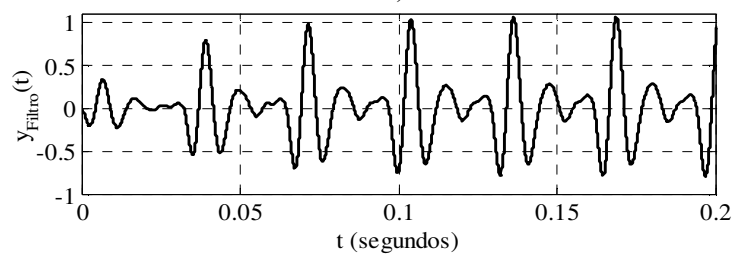

Fig. 4. a) Nota Si produzida pelo baixo; b) sinal gerado pelo filtro.

Na Figura 5 é apresentado o espectro em frequiência dos dois sinais. As duas maiores amplitudes de ambos os espectros normalizados estão em torno da mesma frequiência. O corpo do baixo atenuou muito a freqüência fundamental da nota $\mathrm{Si}$, o que também aconteceu na filtragem do sinal dente de serra. A $2^{\mathrm{a}} \mathrm{e}$ $5^{\mathrm{a}}$ harmônicas têm amplitudes semelhantes em ambos os espectros $Y_{s i}(f)$ e $Y_{\text {Filtro }}(f)$, porém a $6^{\mathrm{a}}$ harmônica apresenta uma diferença maior. A partir da $7^{\mathrm{a}}$ harmônica as amplitudes são praticamente desprezíveis nos dois espectros.

Ouvindo os dois sinais, nota-se que eles são parecidos, porém existe uma diferença entre eles. Esta é causada pelo decaimento natural, ou seja, o sinal gerado pelo baixo diminui de intensidade com o tempo, enquanto que no sinal filtrado isso não ocorre.

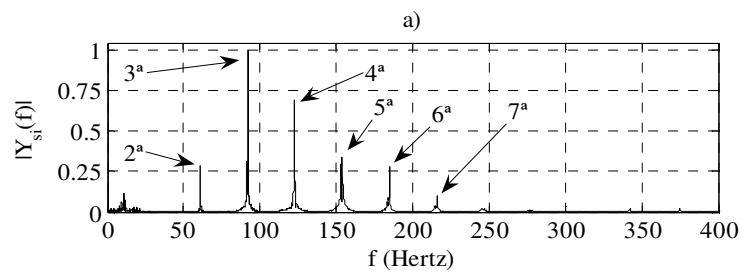

b)

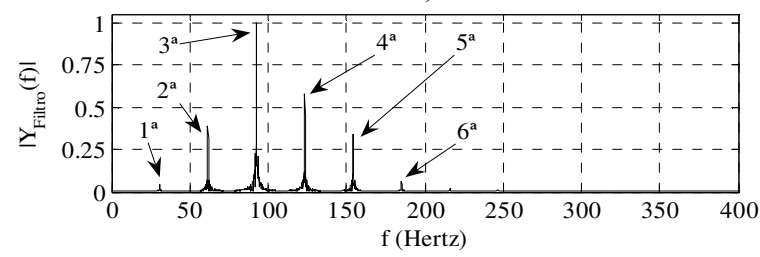

Fig. 5. Espectro em freqüência normalizado: a) nota Si do baixo $y_{s i}(t)$;

b) dente de serra filtrado $y_{\text {Filtro }}(t)$. São indicadas as posições das harmônicas em cada espectro.

\section{CONCLUSÕES}

Os resultados apresentados nas Figuras 4 e 5 mostram que um filtro digital pode modelar adequadamente o corpo de um baixo. Acusticamente os sinais obtidos na saída da cascata de filtros alimentados pelo dente de serra e o som real gerado pelo instrumento são parecidos. O dente de serra mostrou ser uma boa solução para a excitação do filtro.

O decaimento natural no domínio do tempo que ocorre ao tocar uma corda não foi levado em conta, pois precisa de uma análise mais detalhada de como modelar esse efeito nas cordas do instrumento. Este problema está em estudo atualmente.

\section{REFERÊNCIAS}

[1] K. Bradley, M. Cheng and V. L. Stonick, "Automated analysis and computationally efficient synthesis of acoustic guitar strings and body", IEEE ASSP Workshop on Applications of Signal Processing to Audio and Acoustics, p. 238-241, Outubro 1995.

[2] M. Karjalainen, V. Välimäki and Z. Jánosy, "Toward high-quality sound synthesis of the guitar and string instruments", Proceedings of the ICUC, p. 56-63, Setembro 1993.

[3] C. Traube and J. O. Smith III, "Extracting the fingering and the plucking points on a guitar string from a recording", IEEE Workshop on the Applications of Signal Processing to Audio and Acoustics, p. 7-10, 2001.

[4] A. V. Oppenheim, R. W. Schafer and J. R. Buck, Discrete-time signal processing. Prentice Hall, 1999.

[5] V. Stonick and K. Bradley, Labs for signals and systems using Matlab. PWS BookWare Companion Series, 1996. 